\title{
Adubação verde com crotalária consorciada ao minimilho antecedendo a couve-folha sob manejo orgânico
}

\author{
André Luiz Corrêa ${ }^{1}$, Antônio Carlos de Souza Abboud², José Guilherme Marinho Guerra ${ }^{3}$, \\ Luiz Augusto de Aguiar ${ }^{4}$, Raul de Lucena Duarte Ribeiro ${ }^{2}$ \\ http://dx.doi.org/10.1590/0034-737X201461060010
}

\begin{abstract}
RESUMO
Este experimento foi realizado em Seropédica, RJ, com três tratamentos de cultivos para adubação verde, compostos por milho, consórcio de milho com crotalária e crotalária, em blocos ao acaso. Durante o crescimento, realizou-se a colheita de minimilho. Após o corte das plantas, os tratamentos foram combinados com duas formas de preparo do solo: plantio direto e preparo convencional, em esquema de subparcelas, com posterior plantio de couve-folha. As avaliações constaram de produção de matérias fresca e seca e acúmulo de nutrientes da parte aérea dos adubos verdes; produtividade, peso de palha e número de espigas; acúmulo de nutrientes nas espigas; comprimento, diâmetro e peso de espigas de minimilho e número de espigas por planta; produtividade, número de folhas, área foliar, matéria seca, produtividade por colheita, área específica por colheita e acúmulo de $\mathrm{N}$ na couve-folha, e balanço de $\mathrm{N}$ no sistema. O monocultivo de milho proporcionou produtividade e número de espigas de minimilho comerciais maiores (respectivamente 797,2 $\mathrm{kg} \mathrm{ha}^{-1}$ e 123.785 un ha $^{-1}$ ), bem como maior acúmulo de N, P, Ca e Mg nas espigas despalhadas e de N, K e Ca na palha das espigas. O consórcio proporcionou maior número de espigas por planta $(0,91)$. A maior produção de biomassa foi proporcionada pelo consórcio de crotalária e milho (7,43 $\left.\mathrm{Mg} \mathrm{ha}^{-1}\right)$. O acúmulo de nitrogênio proporcionado pelo consórcio foi superior ao do monocultivo de milho e equivalente ao do monocultivo de crotalária. Na couvefolha, houve diferença apenas na emissão de folhas (1.967.083 un ha' ${ }^{-1}$ ), com superioridade do plantio direto.
\end{abstract}

Palavras-chave: Brassica oleracea var. acephala, Crotalaria juncea, Zea mays, agroecologia, agricultura orgânica, plantio direto.

\section{ABSTRACT}

\section{Green manure by intercropping crotalaria with baby corn before kale under organic management}

The experiment was conducted in Seropédica, State of Rio de Janeiro, with three treatments for green manure, composed of corn, corn intercropped with crotalaria, and crotalaria, in randomized blocks. Baby corn was harvestedduring growth. After cutting the plants, the treatments were combined with two ways of soil preparation: no-tillage and conventional preparation, in a subplot design, with subsequent planting of kale. The evaluations werethe following: production of fresh and dry matter and accumulation of nutrients in the aerial part of green manures; yield, straw weight and number of ears; nutrient accumulation in the ears; length, diameter, and weight of the baby corn ears and number of ears per plant; yields, number of leaves, leaf area, dry matter, yield per harvest, specific area per harvest and accumulation of $\mathrm{N}$ in the kale; and balance of $\mathrm{N}$ in the system. Corn monoculture provided good

Recebido para publicação em 23/03/2013 e aprovado em 20/02/2014

${ }^{1}$ Engenheiro-Agrônomo, Mestre. Avenida Marechal Paulo Torres, 415, 07/204, Centro, 27.700-000, Vassouras, Rio de Janeiro, Brasil. andreagroeco@hotmail.com (autor para correspondência).

${ }^{2}$ Engenheiro-Agrônomo, Doutor. Departamento de Fitotecnia, Universidade Federal Rural do Rio de Janeiro, Caixa Postal 74583, BR 465, km 07, 23.890-000, Seropédica, Rio de Janeiro, Brasil.

Engenheiro-Agrônomo, Doutor. Embrapa Agrobiologia, Caixa Postal 74505. BR 465, km 07, 23.890-000, Seropédica, Rio de Janeiro, Brasil.

${ }^{4}$ Engenheiro-Agrônomo, Mestre. Centro de Pesquisa em Agricultura Orgânica, Empresa de Pesquisa Agropecuária do Estado do Rio de Janeiro, BR 465, km 07, 23.890-000, Seropédica, Rio de Janeiro, Brasil.

Rev. Ceres, Viçosa, v. 61, n.6, p. 956-963, nov/dez, 2014 
yields and a greater number of commercially viable baby corn ears (797.2 $\mathrm{kg} \mathrm{ha}^{-1}$ and $123,785 \mathrm{un} \mathrm{ha}^{-1}$, respectively), as well as higher concentrations of $\mathrm{N}, \mathrm{P}, \mathrm{Ca}$ and $\mathrm{Mg}$ in the dehusked ears and of $\mathrm{N}, \mathrm{K}$, and $\mathrm{Ca}$ in the straw of the husks whereas the intercropping provided a greater number of ears per plant $(0.91)$. The highest biomass yield was provided by crotalaria and corn intercropping $\left(7.43 \mathrm{Mg} \mathrm{ha}^{-1}\right)$. The accumulation of nitrogen provided by the intercropping was greater than the corn monoculture, but equivalent to the crotalaria monoculture. For the kale, there was a difference only in the output of leaves $\left(1,967,083\right.$ un ha $\left.^{-1}\right)$, in which the no-tillage system was higher.

Key words: agroecology, Brassica oleracea var. acephala, Crotalaria juncea, no-tillage, organic agriculture, Zea mays.

\section{INTRODUÇÃO}

As leguminosas herbáceas constituem algumas das espécies mais utilizadas como adubos verdes, embora outras espécies também possam ser. Ocorre que as leguminosas, além de proporcionarem benefícios similares aos obtidos com espécies utilizadas para a adubação verde, têm como particularidade o fato de formarem associações simbióticas com bactérias fixadoras de nitrogênio atmosférico, proporcionando, desta forma, a incorporação de quantidades expressivas deste nutriente essencial nos sistemas de cultivo. Por essa característica, no que se refere ao aumento do estoque de matéria orgânica do solo, as leguminosas, além de contribuírem com a sua produção de biomassa, contribuem para aumento da biomasssa dos cultivos subsequentes.

A mistura de espécies de diferentes grupos podem aumentar a produção de biomassa por área, além de evitar a lixiviação de nutrientes e permitir a exportação mais eficiente dos nutrientes que seriam retidos no solo (Kahmen et al., 2006). Miyazawa et al. (2010), em experimento com C. juncea, sorgo (Sorghum bicolor) e girassol (Helianthus annuus), observaram maior produção de matéria seca e padrão de enraizamento mais profundo com plantios consorciados, em relação aos dos monocultivos dessas espécies.

Em experimento conduzido por Perin et al. (2006), em ausência de fertilizante nitrogenado e com cultivo prévio de $C$. juncea, consorciada com milheto, obteve-se maior produtividade do milho do que com o pré-cultivo de crotalária solteira, resultado que não se repetiu quando houve aplicação de fertilizante nitrogenado $(90 \mathrm{~kg}$ de N $h^{-1}{ }^{-1}$. Segundo os autores, esse efeito deve-se à liberação de $\mathrm{N}$, mais sincronizada com o requerimento do milho do que ocorre com crotalária e milheto solteiros.

Outro exemplo de benefício do consórcio de leguminosas com gramíneas é a fixação biológica de nitrogênio (FBN). Hödtke et al., (1999), trabalhando com milho consorciado com caupi (Vigna unguiculata) ou soja (Glycine max), verificaram que a FBN foi aumentada pelo consórcio.
Em sistemas de plantio direto, vários autores recomendam o consórcio de gramíneas com leguminosas para a produção de palhada (Calegari et al., 1993; Merten \& Fernandes, 1998). Trabalho realizado por Silva et al. (2009), em que avaliaram diferentes consórcios de milho e sorgo com outras espécies, encontraram maiores valores para produção de biomassa com o consórcio dessas gramíneas com C. juncea, guandu (Cajanus cajan) e tremoço-branco (Lupinus albus).

Cazetta et al. (2005) compararam cultivos isolados e consorciados de milheto e $C$. juncea. Constataram que o cultivo consorciado produziu mais biomassa e maior acúmulo de $\mathrm{N}$ na palhada do que o monocultivo de crotalária e que a persistência da palhada do consórcio foi equivalente à do milheto isolado. Outros autores, como Risso et al. (2009), ao avaliarem consórcios de milho com leguminosas (C. juncea e Mucuna pruriens) para fins de adubação verde, observaram vantagens quanto à biomassa total produzida por unidade de área cultivada.

Silva (2002), ao trabalhar com o consórcio entre sorgo (S. bicolor) e crotalária (C. juncea), antecedido do cultivo de brócolis (Brassica oleraceae var. italica), sob manejo orgânico, em sistema de plantio direto, obteve produções de matéria seca no consórcio e no monocultivo com crotalária equivalentes $(8,97$ e 8,02 $\mathrm{Mg} \mathrm{ha}^{-1}$, respectivamente). Fato semelhante foi observado por Santos et al. (2009), em cultivo orgânico de milho-verde, em sistema de plantio direto na palhada de diferentes espécies, quando verificaram valores equivalentes de produção de matéria seca que não diferiram entre o monocultivo de $C$. juncea e o consórcio desta com sorgo.

Há a possibilidade de utilização de leguminosas consorciadas com o milho, pois além de ser comum o seu cultivo, principalmente no período de primavera-verão, isso pode, já na fase de pré-cultivo como adubo verde, permitir a colheita de espiguetas imaturas, comercializadas como minimilho. O minimilho é a inflorescência feminina do milho antes da polinização, ou seja, é a espiga de milho em desenvolvimento (Queiroz \& Pereira 
Filho, 2010). Todavia, ajustes fazem-se necessários para uma utilização eficiente desses consórcios.

O objetivo deste trabalho foi avaliar o efeito do consórcio de milho (Zea mays) para colheita de minimilho com crotalária ( $C$. juncea) sobre a produção de couvefolha (Brassica oleracea var. acephala) sob manejo orgânico.

\section{MATERIAL E MÉTODOS}

O trabalho foi realizado na área do Sistema Integrado de Produção Agroecológica (SIPA), denominado "Fazendinha Agroecológica Km 47", município de Seropédica, Estado do Rio de Janeiro, localizado em $22^{\circ}$ $45^{\prime} \mathrm{S}, 43^{\circ} 41^{\prime} \mathrm{O}$, em altitude de $33 \mathrm{~m}$ e clima classificado como Aw (Neves et al., 2005). O solo da área experimental é classificado como um Argissolo VermelhoAmarelo (Embrapa, 1997).

O experimento constou de duas etapas, sendo a primeira, para adubação verde, formada pelo monocultivo de milho (200.000 plantas ha-1), monocultivo de $C$. juncea (300.000 plantas ha-1) e o consórcio entre essas espécies (100.000 plantas ha-1 de milho e 150.000 plantas ha ${ }^{-1}$ de $C$. juncea), todos implantados em solo preparado convencionalmente. $\mathrm{O}$ delineamento experimental foi o de blocos casualizados com oito repetições. Cada unidade experimental media $4 \mathrm{~m} \times 4 \mathrm{~m}$.

Os resultados da análise de fertilidade do solo não revelaram a necessidade de correção de acidez ou de uso de fertilizantes fosfatados, mas indicaram a necessidade de adubação potássica, como evidencia o resultado analítico: $\mathrm{pH}=6,3 ; \mathrm{Al}=0,0 \mathrm{cmol}_{\mathrm{c}} / \mathrm{dm}^{3} ; \mathrm{Ca}+\mathrm{Mg}=$ $4,4 \mathrm{cmol} / \mathrm{dm}^{3} ; \mathrm{P}=142,9 \mathrm{mg} / \mathrm{dm}^{3}, \mathrm{~K}=55 \mathrm{mg} / \mathrm{dm}^{3}$ e $\mathrm{C}$ $=1,05 \%$. No entanto, não se realizou qualquer tipo de adubação de plantio ou de cobertura por ocasião da semeadura, a qual ocorreu em 24/02/2010, mantendo-se, após a germinação das sementes, oito plantas de milho e doze de $C$. juncea por metro linear, sendo as linhas de plantio distanciadas $0,40 \mathrm{~m}$ uma das outras, em todos os tratamentos. As parcelas compostas pelo consórcio foram arranjadas com linhas alternadas de milho e de crotalária. A variedade de milho utilizada foi a Nitrodente.

A colheita de minimilho foi realizada em área útil de $7,2 \mathrm{~m}^{2}$, centralizada nas parcelas de milho e de milho consorciado com crotalária, no período de 20/04 a 17/ 05/2010, perfazendo um total de oito colheitas.

Quatro dias antes do corte dos adubos verdes, que ocorreu em 14/06/2010, avaliou-se a matéria fresca produzida, a qual foi determinada pela pesagem do material da área de 1,0 m², centralizada, nas parcelas com milho, crotalária e consórcio. As avaliações também constaram da produção de matérias fresca e seca e determina- ção do acúmulo de nitrogênio $(\mathrm{N})$ da parte aérea dos adubos verdes, peso de palha e número, comprimento, diâmetro e peso das espiguetas (minimilho), número de espigas produzidas por planta e acúmulo de $\mathrm{N}$ nas espiguetas. Considerou-se como espiguetas comerciais aquelas com 1,0 a 1,8 cm de diâmetro e com 4,0 a 12,0 $\mathrm{cm}$ de comprimento (Queiroz \& Pereira Filho, 2010), com boa formação e sem danos provocados por pragas ou doenças.

Para a obtenção da matéria seca da parte aérea, foi coletada uma subamostra de $300 \mathrm{~g}$ de cada parcela para secagem em estufa de ventilação forçada, em temperatura de $65^{\circ} \mathrm{C}$, até o material alcançar massa constante. Posteriormente, o material foi processado em moinho tipo Willey (moinho de facas), com malha de 20 mesh, a fim de proceder-se à análise química para a determinação dos teores de $\mathrm{N}$ após digestão sulfúrica e destilação pelo método Kjeldahl.

Após o corte dos adubos verdes, a área cultivada na primeira etapa foi dividida em dois sistemas de preparo de solo, ou seja, plantios direto e convencional, para o transplantio subsequente das mudas de couve-folha (Brassica oleraceae var. acephala), em plantio direto e convencional, caracterizando delineamento experimental em blocos casualizados, com parcelas subdivididas (com pré-cultivos nas parcelas e preparo de solo nas subparcelas), na segunda etapa do experimento.

O plantio direto consistiu na abertura de covas para o plantio de mudas de couve sobre a palhada dos adubos verdes; o preparo convencional do revolvimento da palhada com enxada rotativa acoplada a um microtrator.

A couve-folha escolhida foi o híbrido (F1) Hi Crop, semeado em maio de 2010 e transplantado para a área experimental 30 dias após a semeadura, no espaçamento de $1 \mathrm{~m}$ x 0,5 m, com 32 plantas nas subparcelas, as oito centrais compondo a área útil. Foram fornecidos $9 \mathrm{~g}$ de sulfato de potássio $\left(50 \%\right.$ de $\left.\mathrm{K}_{2} \mathrm{O}\right)$ por cova, na ocasião do plantio. Na mesma ocasião, também foram aplicados $240 \mathrm{~g}$ de esterco bovino $(47,74 \%$ de umidade), por cova.

Em julho de 2010, na primeira colheita de couve, realizou-se adubação de cobertura com $50 \mathrm{~g}$ de farelo de mamona ( $5 \%$ de $\mathrm{N}$ ) por planta, momento em que também foi realizada a capina com enxada apenas nas linhas de plantio. Outras quatro adubações de cobertura com o mesmo fertilizante foram realizadas em intervalos de 30 dias, sendo que, na terceira adubação, nova capina foi realizada com enxada apenas nas linhas de plantio. Além das duas capinas, o controle da vegetação espontânea deu-se por roçadas quinzenais com motorroçadeira. A irrigação de experimento foi realizada por aspersão; a colheita foi realizada semanalmente, por um período de seis meses, em quatro plantas da área útil, escolhidas aleatoriamente. 
Foram avaliados produtividade, número de folhas, área foliar, matéria seca, produtividade por colheita, área específica por colheita (relação entre a área foliar e a matéria seca), acúmulo de $\mathrm{N}$ na couve e balanço do $\mathrm{N}$ no sistema, sendo estes dois últimos parâmetros estimados a partir de médias dos valores do nitrogênio de seis colheitas de couve, cada uma pertencente a um dos meses do período total de colheita. A área foliar e a matéria seca foram avaliadas a partir de dez folhas, escolhidas ao acaso, em cada uma das colheitas. Na determinação da matéria seca e do N, os procedimentos foram os mesmos utilizados nos adubos verdes. Para a obtenção da área foliar, utilizou-se o integrador marca LI-COR, modelo LI - 3100.

A contribuição da FBN foi estimada utilizando-se a técnica de abundância natural de ${ }^{15} \mathrm{~N}$ ou ä ${ }^{15} \mathrm{~N}$ (Shearer \& Kohl, 1988), com espectrômetro de massa (Finnigan MAT, modelo Delta Plus). A contribuição percentual de nitrogênio derivado da FBN foi calculada por meio da fórmula: $\%$ FBN $=100\left(\ddot{a}^{15} \mathrm{~N}\right.$ da planta testemunha $-\ddot{a}^{15} \mathrm{~N}$ da planta fixadora $) /\left(\ddot{a}^{15} \mathrm{~N}\right.$ da planta testemunha $\left.-\mathrm{B}\right)$, sendo $\mathrm{B}=$ 1,31 , valor correspondente à discriminação isotópica de ${ }^{15} \mathrm{~N}$, feita pela $C$. juncea, conforme descrito por Okito et al. (2004), adotado como estimativa das demais espécies. Como referência de plantas não fixadoras de $\mathrm{N}_{2}$ (testemunha), foram utilizados o milho, o girassol e o quiabo, também cultivados na área experimental. Tanto para a $C$. juncea como para as plantas testemunhas foram utilizadas três amostras.

A análise estatística foi realizada por meio do programa SAEG versão 9.1, iniciada por testes de homogeneidade e normalidade. Posteriormente, procedeu-se à análise da variância dos dados, com aplicação do "teste F", a 5\% de probabilidade e, quando constatada diferença significativa, utilizou-se o teste de comparação entre médias de Tukey, a 5\% de probabilidade. Em relação à contribuição da FBN, os resultados foram submetidos ao teste t, a $5 \%$ de probabilidade, para comparação entre as médias.

\section{RESULTADOS E DISCUSSÃO}

Observou-se efeito na produtividade de matérias fresca e seca das espigas despalhadas comerciais e da palha das espiguetas colhidas, bem como no número das espigas comerciais e não comercias, com o monocultivo de milho mostrando-se estatisticamente superior em relação a essas variáveis. Houve ainda efeito significativo para o número de espiguetas por planta, o qual evidenciou a superioridade do consórcio com a leguminosa, em relação a essa variável (Tabela 01).

Observa-se que o consórcio produziu o equivalente a $65,17 \%$ das espiguetas despalhadas comerciais produzidas pelo monocultivo, fato que permite especular sobre

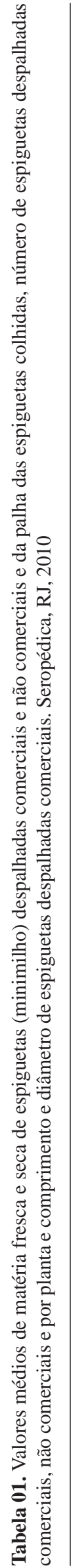

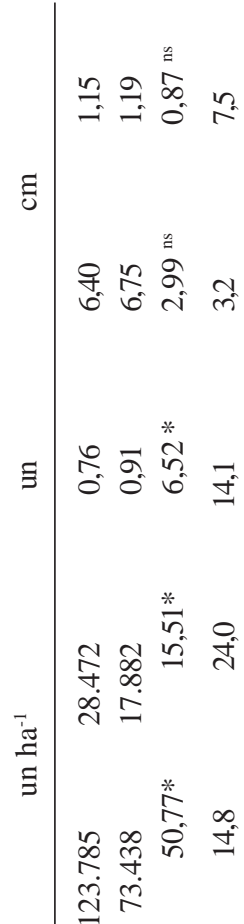

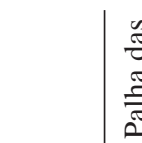

莡

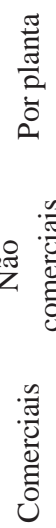
$\frac{\substack{\frac{n}{0} \\ 0}}{\stackrel{0}{0}}$

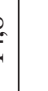

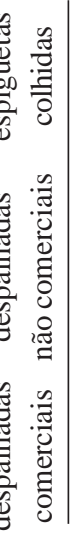

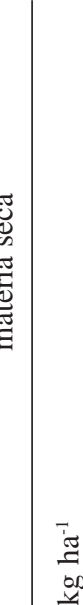

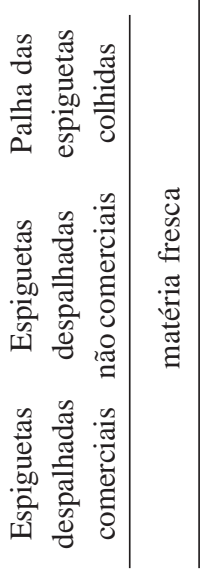

(1)

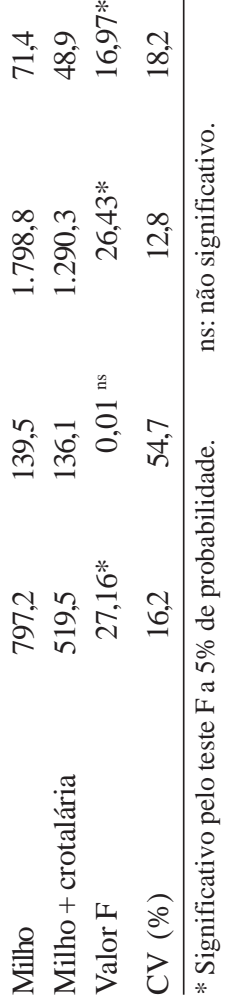


algum tipo de favorecimento ocorrido por conta da presença da crotalária, o que pode ter minimizado o efeito de competição intraespecífica entre as plantas de milho.

Os dados obtidos são semelhantes aos observados por Pereira Filho (1998), que utilizando os cultivares de milho CMS 43 (Pipoca) e BR 400 (Superdoce), em quatro diferentes densidades de plantio, obteve produtividades de espigas comerciais entre 632 e $1.040 \mathrm{~kg} \mathrm{ha}^{-1}$; bem como aos de Almeida (2004), que, avaliando dez cultivares de milho para a produção de minimilho, registrou produtividades de espigas comerciais entre 166,5 e $1.338,2 \mathrm{~kg} \mathrm{ha}^{-1}$, e de Carvalho (2002), que, avaliando o desempenho de oito cultivares de milho para a produção de minimilho, em três diferentes épocas de plantio, também obteve produtividades entre 390 e $1480 \mathrm{~kg} \mathrm{ha}^{-1}$.

Matérias fresca e seca das espiguetas despalhadas não comerciais, bem como seu diâmetro e comprimento não foram influenciados pelos tratamentos.

A maior parte do minimilho foi obtida entre a terceira e sexta colheitas, período responsável por $87,88 \%$ do minimilho colhido no monocultivo de milho e por $82,07 \%$ no consórcio com crotalária. Em ambos os tratamentos, a quarta colheita mostrou-se a de maior rendimento, sendo responsável por $27,64 \%$ do minimilho, colhido no monocultivo, e por $29,66 \%$, no consórcio.

Quanto ao acúmulo de $\mathrm{N}$ presente na matéria seca das espiguetas e de suas palhas, houve superioridade do monocultivo de milho. (Tabela 02).

Tabela 02. Acúmulo de nitrogênio nas espiguetas despalhadas e em suas palhas. Seropédica, RJ, 2010

\begin{tabular}{lcc}
\hline & \multicolumn{2}{c}{$\mathbf{N}$} \\
\cline { 2 - 3 } & \multicolumn{2}{c}{ kg ha $^{-1}$} \\
\hline Tratamentos & Espiguetas despalhadas & Palhas \\
Milho & 2,74 & 3,98 \\
Milho + crotalária & 2,08 & 2,75 \\
Valor F & $11,75^{*}$ & $13,07^{*}$ \\
\hline CV $(\%)$ & 15,94 & 20,12 \\
\hline
\end{tabular}

* Significativo pelo teste $\mathrm{F}$ a $5 \%$ de probabilidade. ns: não significativo.

Tabela 03. Matéria seca e acúmulo de nitrogênio na parte aérea dos adubos verdes. Seropédica, RJ, 2010

\begin{tabular}{lcc}
\hline Tratamentos & Matéria secaMg ha & Nkg ha \\
\hline Milho & $4,90 \mathrm{c}$ & $39,70 \mathrm{~b}$ \\
Milho + crotalária & $7,43 \mathrm{a}$ & $179,69 \mathrm{a}$ \\
Crotalária & $6,07 \mathrm{~b}$ & $176,53 \mathrm{a}$ \\
\hline CV $(\%)$ & 6,3 & 16,1 \\
\hline
\end{tabular}

* Médias seguidas da mesma letra não diferem estatisticamente entre si pelo teste de Tukey a $5 \%$ de probabilidade.
Na produção de matéria seca e no acúmulo de $\mathrm{N}$ da parte aérea dos adubos verdes, houve diferença significativa entre os tratamentos (Tabela 03). Em relação à matéria seca, o consórcio proporcionou maiores valores e verificou-se que $60,2 \%$ foram provenientes da crotalária e $39,8 \%$ do milho. Na mesma área experimental, Pereira (2004), testando diferentes densidades populacionais de $C$. juncea em duas épocas de plantio, obteve produtividades entre 5,25 e 11,02 $\mathrm{Mg} \mathrm{ha}^{-1}$ de matéria seca em plantio realizado na segunda quinzena de novembro. $\mathrm{O}$ mesmo autor, em plantio realizado na primeira quinzena de abril, obteve produtividades entre 1,26 e $6,66 \mathrm{Mg}^{-}$ ${ }^{1}$ de matéria seca. Em outro trabalho, realizado em 2007 , o mesmo autor obteve $17,6 \mathrm{Mg} \mathrm{ha}^{-1}$ de massa seca com C. juncea. Silva et al. (2009), testando diferentes consórcios para adubação verde cultivados sobre palhada de lab-lab (Dolichos lablab), em consórcio de milho (37.500 plantas ha ${ }^{-1}$ ) com C. juncea (137.500 plantas $\mathrm{ha}^{-1}$ ), obtiveram $10,31 \mathrm{Mg} \mathrm{ha}^{-1}$ de matéria seca. Os valores de biomassa alcançados por esses autores são elevados, considerando-se que a semeadura foi realizada no mês de março, momento menos propício para a produção de biomassa pelas espécies utilizadas. No entanto, estes experimentos foram beneficiados por uma adubação de plantio com $200 \mathrm{~kg} \mathrm{ha}^{-1}$ do fertilizante formulado NPK 08-28-16, além do efeito da palhada de lab-lab remanescente na área. Por outro lado, o aporte de $\mathrm{N}$ pode ter prejudicado a FBN na crotalária, pois o acúmulo desse nutriente, obtido pelos autores, mesmo com uma produção de matéria seca superior à alcançada neste trabalho, foi de $163,20 \mathrm{~kg} \mathrm{ha}^{-1}$, valor $10,10 \%$ inferior ao aqui obtido.

No que se refere ao acúmulo de $\mathrm{N}$, houve superioridade do consórcio de milho com crotalária e do monocultivo de crotalária em relação ao monocultivo de milho, o que é um fato esperado, em vista da contribuição da FBN realizada pela leguminosa. No entanto, a superioridade do consórcio da crotalária com uma gramínea nem sempre é evidenciada. Perin (2005), em experimento com adubação verde com $C$. juncea e milheto (Pannisetum glaucum), obteve maiores valores de $\mathrm{N}$ no monocultivo de crotalária e menores valores no consórcio de crotalária e milheto. Em outra avaliação de consórcios, Perin et al. (2004) obtiveram acúmulo de 305,04 e 218,49 $\mathrm{kg} \mathrm{ha}^{-1}$ de $\mathrm{N}$ com $C$. juncea e com o consórcio dessa com milheto. No entanto, cabe ressaltar que os experimentos desses dois trabalhos foram instalados no mês de novembro, o que permitiu que a maior parte do desenvolvimento da leguminosa ocorresse sob condições de dias mais longos, favorecendo a produção de biomassa e, consequentemente, o acúmulo de N. Todavia, a escolha do consórcio com a gramínea pode favorecer a manutenção da palhada no solo por mais 
tempo, dada a sua maior relação $\mathrm{C} / \mathrm{N}$, em comparação com a do monocultivo de crotalária. Ainda, caso a gramínea escolhida seja o milho, poderá haver a obtenção do minimilho, produto de valor comercial, ainda na fase de adubação verde.

Em trabalho realizado na mesma área experimental com diferentes espécies do gênero Crotalaria, Pereira (2007) registrou, em $C$. juncea, acúmulos de $\mathrm{N}$ superior ao encontrado neste trabalho, chegando a $446,5 \mathrm{~kg} \mathrm{ha}^{-1}$. Teodoro et al. (2011), avaliando o desempenho de leguminosas no cerrado brasileiro, obteve acúmulo de $\mathrm{N}$ de $514 \mathrm{~kg} \mathrm{ha}^{-1}$ pela $C$. juncea, valor próximo ao triplo do aqui encontrado. No entanto, nesses casos os experimentos desses dois trabalhos foram instalados no mês de novembro, o que permitiu o melhor desenvolvimento da leguminosa .

No que se refere ao efeito dos adubos verdes, na couve plantada após seu corte, observou-se diferença significativa do plantio direto em relação ao convencional no número de folhas, mas sem interação entre o preparo do solo e os cultivos para adubação verde. A produtividade no plantio direto foi $9,10 \%$ maior do que a observada no plantio com preparo convencional do solo, mas sem diferença significativa.

Silva et al. (2011), testando cultivos para rotação e consórcios com leguminosas, na mesma localidade, obti- veram, em dois plantios diretos de outro híbrido de couve (HS 20 - F1) consorciados com Crotalaria spectabilis, consorciado com C. juncea, 42,97 e 24,84 $\mathrm{Mg} \mathrm{ha}^{-1}$,de matéria fresca respectivamente, sendo que o segundo plantio foi realizado após o cultivo de milho para o consumo verde. $\mathrm{O}$ primeiro valor observado pelo autor foi próximo do encontrado neste trabalho, sendo o segundo bem inferior. No entanto, nas duas condições, a emissão de folhas, respectivamente $1.518 .236 \mathrm{e}$ 1.244.593 um ha-1, foi inferior à aqui observada.

Quanto ao N acumulado na parte aérea da couve, houve diferença significativa entre os sistemas de plantio, com o acúmulo com o plantio direto sendo superior ao com o preparo convencional do solo (Tabela 04). É possível que isso tenha sido favorecido pela manutenção da palhada na superfície do solo, o que geralmente confere uma mineralização mais lenta da matéria orgânica, em relação à incorporada ao solo, o que pode ter permitido a liberação de $\mathrm{N}$ de forma mais concatenada com a demanda das plantas pelo nutriente.

No que se refere à FBN, para a crotalária solteira, a estimativa foi de $49,68 \%$ e, para a crotalária consorciada com milho, 53,92\% (Tabela 05). O fato de a contribuição ser superior no consórcio deve-se, provavelmente, ao de a gramínea ter maior capacidade de competir pelo $\mathrm{N}$ do

Tabela 04. Produtividade, matéria seca, número de folhas, área foliar e acúmulo de nitrogênio da couve-folha. Seropédica, RJ, 2010

\begin{tabular}{|c|c|c|c|c|c|}
\hline & Produtividade & $\begin{array}{c}\text { Matéria } \\
\text { seca }\end{array}$ & \multirow{2}{*}{$\begin{array}{c}\begin{array}{c}\text { Número } \\
\text { de folhas }\end{array} \\
\text { un ha }^{-1}\end{array}$} & \multirow{2}{*}{$\begin{array}{c}\begin{array}{c}\text { Área } \\
\text { foliar }\end{array} \\
\mathbf{m}^{2}\end{array}$} & \multirow{2}{*}{$\begin{array}{c}\mathrm{N} \\
\mathrm{kg} \mathrm{ha} \mathbf{h}^{-1}\end{array}$} \\
\hline & \multicolumn{2}{|c|}{ Mg ha ${ }^{-1}$} & & & \\
\hline Plantio direto & 46,03 & 4,33 & 1.967 .083 & 75,87 & 178,86 \\
\hline Plantio com preparo convencional do solo & 42,19 & 4,13 & 1.917 .083 & 69,49 & 164,61 \\
\hline Valor F & $7,8^{\mathrm{ns}}$ & $2,74^{\text {ns }}$ & $28,27 *$ & $8,84^{\mathrm{ns}}$ & $9,35^{*}$ \\
\hline $\mathrm{CV}(\%)$ & 7,6 & 7,0 & 1,2 & 7,2 & 6,6 \\
\hline Milho & $42,38 \mathrm{a}$ & $4,10 \mathrm{a}$ & $1.930 .625 \mathrm{a}$ & $69,71 \mathrm{a}$ & $163,42 \mathrm{a}$ \\
\hline Milho + crotalária & $44,54 \mathrm{a}$ & $4,21 \mathrm{a}$ & $1.942 .500 \mathrm{a}$ & 73,67 a & $170,97 \mathrm{a}$ \\
\hline Crotalária & $45,43 \mathrm{a}$ & $4,39 \mathrm{a}$ & $1.953 .125 \mathrm{a}$ & 74,65 a & $180,81 \mathrm{a}$ \\
\hline $\mathrm{CV}(\%)$ & 7,5 & 7,5 & 3,1 & 7,7 & 8,5 \\
\hline
\end{tabular}

* Significativo pelo teste $\mathrm{F}$ a $5 \%$ de probabilidade.

** Médias seguidas da mesma letra não diferem estatisticamente entre si pelo teste de Tukey a 5\% de probabilidade. ns: não significativo.

Tabela 05. Valores de abundância natural de ${ }^{15} \mathrm{~N}\left(\ddot{a}^{15} \mathrm{~N}\right)$ da leguminosa utilizada na adubação verde e contribuição da fixação biológica de nitrogênio (FBN). Seropédica, RJ, 2010

\begin{tabular}{lccc}
\hline Tratamento & $\boldsymbol{\delta}^{\mathbf{1 5}} \mathbf{N}(\boldsymbol{\%})^{(\mathbf{1})}$ & FBN $(\boldsymbol{\%})$ & FBN $^{\left(\mathbf{k g} \mathbf{h a}^{\mathbf{1}}\right)}$ \\
\hline Milho + Crotalária & 3,95 & 53,92 & 78,00 \\
Crotalária & 4,53 & 49,68 & 87,70 \\
Valor t & & $6,14^{*}$ & $2,69^{*}$ \\
\hline
\end{tabular}

* Significativo pelo teste t a $5 \%$ de probabilidade.

(1) $\mathrm{O}$ valor de $\ddot{a}^{15} \mathrm{~N}$ da planta não fixadora de $\mathrm{N}_{2}$ foi $10,34 \pm 0,161$, em que se utilizou uma amostra de cada uma das espécies: milho, girassol e quiabo. 


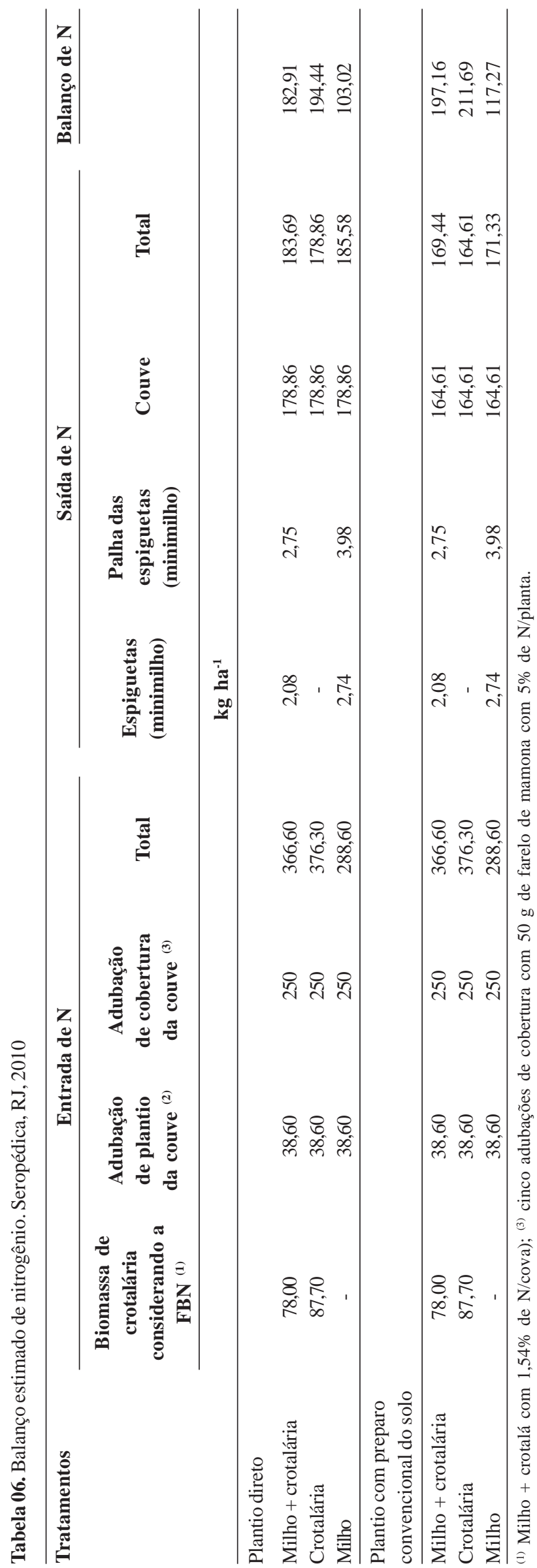

solo. Perin et al. (2004) encontraram a mesma tendência, ao avaliar a contribuição da FBN em plantios de $C$. juncea solteira e em consórcio com milheto.

Para o balanço de N, também a partir de valores estimados por médias, todas as diferenças entre entrada e saída foram positivas, demonstrando que as colheitas de minimilho e de couve exportaram pouco mais da metade do $\mathrm{N}$ estimado no sistema (Tabela 06), sendo os maiores valores associados aos cultivos combinados com o plantio direto, que exportaram, em média, $8,46 \%$ a mais do que os cultivos associados ao plantio com preparo convencional do solo, provavelmente pelo fato de o primeiro tratamento ter apresentado uma produtividade $9,10 \%$ superior à do segundo, demandando mais $\mathrm{N}$ para a formação de folhas.

As espiguetas e suas palhas colhidas foram responsáveis por 3,77 e 2,74\%, em média, da exportação total de $\mathrm{N}$, respectivamente para os tratamentos com monocultivo de milho e consorciado com crotalária. No entanto, no consórcio com a leguminosa, o $\mathrm{N}$ presente ao final do balanço foi, em média, $6,83 \%$ menor do que no tratamento com monocultivo de crotalária, sugerindo uma vantagem na adoção do consórcio para adubação verde, o qual permite um aporte de $\mathrm{N}$ ao solo para o cultivo seguinte, muito próximo do proporcionado pelo monocultivo de crotalária, e possibilita a obtenção de minimilho, um produto comercializável, ainda na fase de adubação verde. Além disso, é possível que, na palhada formada pelo consórcio, ocorra uma perda um pouco mais lenta de $\mathrm{N}$, em relação à da palhada formada apenas por crotalária, por conta da maior relação $\mathrm{C} / \mathrm{N}$ proporcionada pela biomassa da gramínea.

\section{CONCLUSÕES}

O monocultivo de milho proporcionou produtividade e número de espiguetas de minimilho comerciais superiores aos dos demais tratamentos.

A produção de biomassa proporcionada pelo consórcio de crotalária e milho foi superior a dos monocultivos.

O acúmulo de nutrientes proporcionado pelo consórcio de crotalária e milho foi superior ao do monocultivo de milho e superior, ou equivalente, ao dos monocultivo de crotalária.

O plantio direto conferiu rendimentos comparáveis aos do plantio com preparo convencional do solo para a couve, proporcionando aumento na emissão de folhas.

A opção da adubação verde com o consórcio de milho com crotalária trouxe a vantagem da colheita de minimilho e o manejo adotado permitiu a permanência da maior parte do nitrogênio aportado nos sistemas.

Rev. Ceres, Viçosa, v. 61, n.6, p. 956-963, nov/dez, 2014 


\section{REFERÊNCIAS}

Almeida IP de C (2004) Produções de minimilho, espigas verdes e grãos de cultivares de milho. Dissertação de Mestrado. ESAM, Mossoró. $59 \mathrm{p}$.

Calegari A, Mondardo A, Bulisani EA, Costa MBB da, Miyasaka S \& Amado TTJC (1993) Adubação verde no sul do Brasil. $2^{\mathrm{a} e d . ~ R i o ~ d e ~}$ Janeiro, AS-PTA. 346p

Carvalho GS (2002) Caracterização agronômica e nutricional de cultivares de milho sob diferentes condições de cultivo para a produção de minimilho. Dissertação de Mestrado. Lavras, UFLA. 70p

Cazetta DA, Fornasieri Filho D \& Girotto F (2005) Composição, produção de matéria seca e cobertura do solo em cultivo exclusivo e consorciado de milheto e crotalária. Acta Scientiarum Agronomy, 27:575580.

Embrapa (1997) Manual de métodos em análises de solo. $2^{\mathrm{a}} \mathrm{ed}$. Rio de Janeiro, Embrapa Solos. 212p.

Hödtke M, Araújo PA, Köpke U \& Almeida DL de (1999) Nutritional status, grain yield and $\mathrm{N}$-balance of organically grown mayze intercropped with green manure. In: 12th International IFOAM Scientific Conference, Mar del Plata. Procedings, IFOAM. p.135-140.

Kahmen A, Renker C, Unsicker S B \& Buchmann N (2006) Niche complementarity for nitrogen: an explanation for the biodiversity and ecosystem functioning relationship? Ecology, $87: 1244-1255$

Merten GH \& Fernandes FF (1998) Manejo de solo de baixa aptidão. In: Darolt MR Plantio direto: pequena propriedade sustentável. Londrina, IAPAR. p.46-64. (Circular, 101).

Miyazawa K, Murakami T, Takeda M \& Murayama T (2010) Intercropping green manure crops - effects on rooting patterns. Plant Soil, 331:231-239.

Neves MCP, Guerra JGM, Carvalho SR, Ribeiro RLD \& Almeida DL de (2005) Sistema Integrado de Produção Agroecológica ou Fazendinha Ecológica do Km 47. In: Aquino AM de \& Assis RL de (Org.) Agroecologia: princípios e técnicas para uma agricultura sustentável. Embrapa Informação Tecnológica/Embrapa Agrobiologia, Brasília. p.147-172

Okito A, Alves BRJ, Urquiaga S \& Boddey RM (2004) Isotopic fractionation during $\mathrm{N}_{2}$ fixation by four tropical legumes. Soil Biology \& Biochemistry, 36:1179-1190.

Pereira AJ (2004) Produção de biomassa aérea e de sementes de Crotalaria juncea a partir de diferentes arranjos populacionais e épocas do ano. Dissertação de Mestrado. UFRRJ, Seropédica. 68p.

Pereira AJ (2007) Caracterização agronômica de espécies de Crotalaria L. em diferentes condições edafoclimáticas e contribuição da adubação verde com $C$. juncea no cultivo orgânico de brássicas em sistema de plantio direto. Tese de Doutorado. UFRRJ, Seropédica. 72p.
Pereira Filho IA, Gama EEG \& Cruz JC (1998) Minimilho: efeito de densidade de plantio e cultivares na produção e em algumas características da planta de milho. Sete Lagoas, Embrapa Milho e Sorgo. 6p. (Pesquisa em Andamento, 23).

Queiroz VAV \& Pereira Filho IA (2010) Processo de produção de conserva caseira de minimilho. Sete Lagoas, Embrapa Milho e Sorgo. 6p. (Circular Técnica, 140).

Perin A (2005) Desempenho de milho e brócolos em sucessão à adubação verde. Tese de Doutorado. UFV, Viçosa. $86 \mathrm{p}$.

Perin A, Santos RHS, Urquiaga SS, Cecon PR, Guerra JGM \& Freitas GB de (2006) Sunnhemp and millet as green manure for tropical maize production. Scientia Agrícola, 63:453-459.

Perin A, Santos RHS, Urquiaga SS, Guerra JGM \& Cecon PR (2004) Produção de fitomassa, acúmulo de nutrientes e fixação biológica de nitrogênio por adubos verdes em cultivo isolado e consorciado. Pesquisa Agropecuária Brasileira, 39:35-40.

Risso IAM, Guerra JGM, Ribeiro R de LD, Souza CG de, Espíndola JAA \& Polidoro JC (2009) Cultivo orgânico do milho consorciado com leguminosas para fins de adubação verde. Seropédica, Embrapa Agrobiologia. 16p. (Boletim de Pesquisa e Desenvolvimento, 42).

Santos CAB dos, Zandoná SR, Espíndola JAA, Guerra JGM, Souza CG de \& Ribeiro R de LD (2009) Cultivo orgânico do milho verde em sistema de plantio direto na palhada de diferentes espécies de plantas de cobertura de solo. Seropédica, Embrapa Agrobiologia. 19p. (Boletim de Pesquisa e Desenvolvimento, 46).

Shearer G \& Kohl DH (1988) Natural ${ }^{15} \mathrm{~N}$ - abundance a method of eslimding the contribution of biological fixed nitrogen to $\mathrm{N}_{2}$ - fixing systems: potencial for non-legumes. Plant and Soil, $110: 317-327$

Silva EE da, De-Polli H, Guerra JGM, Aguiar-Menezes EL, Resende ALS, Oliveira, FL de \& Ribeiro R de LD (2011) Sucessão entre cultivos orgânicos de milho e couve consorciados com leguminosas em plantio direto. Horticultura Brasileira. 29:4752 .

Silva PCG da \& Foloni JSS (2009) Fitomassa e relação C/N em consórcios de sorgo e milho com espécies de cobertura. Pesquisa Agropecuária Brasileira, 44:1504-1512.

Silva VV (2002) Efeito do pré-cultivo de adubos verdes na produção de orgânica de brócolos (Brassica oleraceae L. var. itálica) em sistema de plantio direto. Dissertação de Mestrado. UFRRJ, Seropédica. $81 \mathrm{p}$.

Teodoro RB, Oliveira FL de, Silva DMN da, Fávero C \& Quaresma MAL (2011) Aspectos agronômicos de leguminosas para adubação verde no cerrado do Alto Vale do Jequitinhonha. Revista Brasileira de Ciência do Solo, 35:635-643. 